Int. J. Electrochem. Sci., 13 (2018) $9618-9629$

International Journal of

ELECTROCHEMICAL

SCIENCE

www.electrochemsci.org

\title{
Three-dimensional Nitrogen-Doped Graphene Aerogel as an Excellent Electrode Material for Highly Sensitive Determination of Midecamycin
}

\author{
Yu Xie, Xue Ma, Yunhui Yu, Peng Zhou, Limin Lu*, Guoying Peng, Xigen Huang, \\ Guangbin Liu*, Wenmin Wang, Haohua He
}

Key Laboratory of Crop Physiology, Ecology and Genetic Breeding, Ministry of Education, Institute of biotechnology and physical agriculture engineering, College of Science, Jiangxi Agricultural University, Nanchang 330045, PR China

*E-mail: lulimin816@ hotmail.com

doi: $10.20964 / 2018.10 .22$

Received: 20 May 2018 / Accepted: 12 July 2018 / Published: 1 September 2018

\begin{abstract}
Abuse of midecamycin (MD) has posed a series of side effects to human health. Therefore, the detection of MD is critical to optimal treatment and avoidance of toxic concentrations. Till now, several carbon materials such as multi-walled carbon nanotube (MWCNT) and graphene modified electrodes were developed for MD determination. However, in relative with these one or twodimensional (1D or 2D) carbon materials, 3D structural materials display more excellent characteristics, such as higher specific surface, better electrical conductivity and more desirable electrocatalytic activity. Inspired by this, in this study, a novel electrochemical MD sensing platform has been proposed based on 3D N-doped graphene aerogels (NGAs) material. Electrochemical results indicate that NGAs modified electrode exhibited prominent sensing performances toward MD, which is mainly ascribed to the fact that the $3 \mathrm{D}$ porous structure provides multiple electron path and unhindered substance diffusion. Besides, the large specific surface area ensures rich active sites for the catalytic reaction of MD. Furthermore, $\mathrm{N}$ doping can effectively adjust their bandgap and electron density. Under the optimized conditions, the as-prepared sensor could detect MD concentrations down to $0.01 \mu \mathrm{M}(\mathrm{S} / \mathrm{N}=3)$ with the linear range of $0.03-21 \mu \mathrm{M}$. The sensor exhibited good performances with high sensitivity, selectivity, and long-term stability.
\end{abstract}

Keywords: Electrochemical sensor; N-doped graphene aerogels; Detection; Midecamycin

\section{$\underline{\text { FULL TEXT }}$}

(C) 2018 The Authors. Published by ESG (www.electrochemsci.org). This article is an open access article distributed under the terms and conditions of the Creative Commons Attribution license (http://creativecommons.org/licenses/by/4.0/). 